\title{
In situ observation of deuterium trapping in self-ion irradiated tungsten
}

\section{$\operatorname{AUTHOR}(\mathrm{S}):$}

Takagi, Ikuji; Yamamichi, Kazuyoshi; Furuta, Yoshinori; Akiyoshi, Masafumi; Sasaki, Takayuki; Tsuchida, Hidetsugu; Hatano, Yuji

\section{CITATION:}

Takagi, Ikuji ...[et al]. In situ observation of deuterium trapping in self-ion irradiated tungsten. Journal of Nuclear Materials 2013, 442(1-3, Supplement 1): \$246-\$250

\section{ISSUE DATE:}

2013-11

URL:

http://hdl.handle.net/2433/179385

\section{RIGHT:}

(C) 2013 Elsevier B.V.; 許諾条件により本文は2013-11-11に公開.; この論 文は出版社版でありません。引用の際には出版社版をご確認ご利用く ださい。; This is not the published version. Please cite only the published version. 


\title{
In situ observation of deuterium trapping in self-ion irradiated tungsten
}

Ikuji Takagi ${ }^{\mathrm{a}}$, Kazuyoshi Yamamichi ${ }^{\mathrm{a}}$, Yoshinori Furuta ${ }^{\mathrm{a}}$, Masafumi Akiyoshi ${ }^{\mathrm{a}}$, Takayuki Sasaki $^{\mathrm{a}}$, Hidetsugu Tsuchida ${ }^{\mathrm{a}}$, Yuji Hatano ${ }^{\mathrm{b}}$

${ }^{a}$ Graduate School of Engineering, Kyoto University, Kyoto Daigaku-Katsura, Nishikyo-ku, Kyoto 615-8540, Japan.

${ }^{b}$ Hydrogen Isotope Research Center, University of Toyama, Gofuku 3190, Toyama 930-8555, Japan

\begin{abstract}
Characteristics of irradiation-induced hydrogen trapping in tungsten were investigated by observing deuterium concentration profiles under continuous deuterium plasma exposure. Tungsten samples called A3 and A4 were 1.5-MeV W irradiated with an average of 0.63 and 4.2 dpa, respectively, and another sample called A5 was 5.0-MeV W irradiated with 54 dpa. Results show that traps were produced around $500 \mathrm{~K}$, a recovery stage of interstitials, and were suggested to migrate from the damaged region to greater depths within the samples. The number of traps significantly increases with displacement at low dpa and then gradually increases around $0.1 \mathrm{dpa}$. Traps are effectively produced at high temperature irradiation. The trapping energy of $0.70 \mathrm{eV}$ in $\mathrm{A} 3$ and $\mathrm{A} 4$ is the same as $\mathrm{He}-$ and $\mathrm{H}$ - irradiated samples. These traps are likely point-defect-like sites that accompany interstitial clusters such as dislocation loops.
\end{abstract}

Corresponding author. takagi@nucleng.kyoto-u.ac.jp (I. Takagi) 


\section{Introduction}

Hydrogen-solid interactions (e.g., solution, diffusion, trapping, and hydriding) are directly related to tritium retention in plasma-facing materials of fusion devices. Tungsten is a candidate material for divertors due to its heat-resistance and high threshold of physical sputtering. Hydrogen-tungsten interactions have been investigated [1] and it is known that hydrogen trapping is a key process for tritium retention. Plasma-facing materials are heavily damaged by fast neutrons from DT reactions and irradiation damage or irradiation-induced defects can act as hydrogen traps.

High energy ions are often used to introduce irradiation damage in tungsten as substitute for fast neutrons [2 - 6]. Wright [6] has shown that irradiation with $12.3 \mathrm{MeV} \mathrm{W}^{4+}$ ions enhances deuterium retention and the retention is likely to saturate below $0.5 \mathrm{dpa}$. Tyburska et al. [5] has observed deuterium retention up to $7 \mu \mathrm{m}$ in $5.5-\mathrm{MeV} \mathrm{W}^{2+}$ irradiated tungsten and shown that the retention is saturated at $0.4 \mathrm{dpa}$ and irradiation-induced traps are removed by $1200 \mathrm{~K}$ annealing. Saturation of the retention is an important phenomenon because it indicates an upper limit of the retention even for heavily damaged tungsten in commercial reactors.

The increase in trapped deuterium at high temperature, typically $500 \mathrm{~K}$, observed in our previous work [7] is also of concern. It suggests that production of the trap depends not only on irradiation damage, but also appropriate temperatures. In the present work, $1.5-\mathrm{MeV}$ and 5.0-MeV W ions were used to irradiate tungsten samples with an average damage level of 0.63 to $54 \mathrm{dpa}$ (1.6 to $110 \mathrm{dpa}$ at peak) at room temperature. The samples were subsequently heated under continuous exposure of a deuterium plasma. By observing deuterium concentration profiles in the samples by nuclear reaction analysis (NRA) during heating, the dependence of trap density and trapping energies were investigated as a function of irradiation dose and temperature. 


\section{Experiments}

\subsection{Sample irradiation}

The W specimens, prepared by A.L.M.T. Co., were disk-shaped with a diameter of 21 $\mathrm{mm}$ and a thickness of $0.5 \mathrm{~mm}$. The W purity was $99.99 \%$ and its main impurities were Mo12, C-10, Fe-6, Al-2 and Cr-2 ppm by weight. After the sample was cut from a rod, which had been stress-relief annealed at $1173 \mathrm{~K}$ for $1 \mathrm{~h}$, it was mechanically polished with abrasive paper and diamond powders, subsequently finished with slurry of colloidal silica, and finally annealed at $1173 \mathrm{~K}$ for $0.5 \mathrm{~h}$ in vacuum. Samples are listed in Table 1, where A1, A2 and B2 in our previous work [7] are also included for comparison of the data. A1 and A2 were irradiated with $0.8-\mathrm{MeV}^{4} \mathrm{He}$ at an angle of $45^{\circ}$ and B2 with $0.2-\mathrm{MeV} \mathrm{H}$ at surface normal.

Samples A3 and A4 were irradiated with $1.5-\mathrm{MeV} \mathrm{W}^{2+}$ ions in Experimental System for Ion Beam Analysis accelerator at Kyoto University. An ion beam 6 x $6 \mathrm{~mm}^{2}$ was vertically irradiated on one side of the sample at room temprature. As the beam current was very low, typically $1.3 \mathrm{nA}\left(1.1 \times 10^{14} \mathrm{~m}^{-2} \mathrm{~s}^{-1}\right)$, no increase in the sample temperature was expected. Irradiation doses for A3 and A4 were $3.0 \times 10^{18}$ and $2.0 \times 10^{19} \mathrm{~m}^{-2}$, respectively. A damage level of the irradiation was represented as a number of displacement estimated by the SRIM2008 code [8], where the displacement energy of tungsten was taken as $90 \mathrm{eV}$ [9]. Displaced atoms extended from the surface to a depth of $0.3-\mu \mathrm{m}$. The average displacement in this region was 0.63 and 4.2 dpa for $\mathrm{A} 3$ and $\mathrm{A} 4$, respectively. Table 1 also lists the peak displacement value.

Sample A5 was irradiated with $5.0-\mathrm{MeV} \mathrm{W}^{4+}$ ions from a pelletron accelerator (Microionbeam Accelerator of Kyoto University). The ion beam was vertically irradiated on one side of the sample at room temprature. The typical beam current was $24 \mathrm{nA}\left(1.2 \times 10^{16} \mathrm{~m}^{-2} \mathrm{~s}^{-1}\right)$ and the sample temperature would not increase significantly. Due to a specific limitation of a 
micro-beam system, the beam size was restricted to $2-\mathrm{mm}$ in diameter. Six points adjacent to each other were irradiated with the same dose of $2.6 \times 10^{20} \mathrm{~m}^{-2}$. The displacement range was $0.8 \mu \mathrm{m}$ and the average displacement was $54 \mathrm{dpa}$.

\subsection{In situ D observation}

The experimental setup has been described elsewhere [10] and will be explained briefly. The sample was set in a vacuum chamber and the ion-irradiated side of the sample was exposed to a deuterium radio-frequency (RF) plasma, where the RF power was $20 \mathrm{~W}$ and deuterium gas pressure was $1 \mathrm{~Pa}$. As the energy of deuterium particles incident to the sample was very low, typically $1 \mathrm{eV}[11]$, there were no effects of defect formation or temperature change. For the entire duration of the experiment, the sample was continuously charged with deuterium from the plasma.

The chamber was connected to a beam duct of the 4MV van de Graaff accelerator at Kyoto University. Deuterium depth profiles near the plasma-exposed surface of the sample were measured by NRA using the reaction of $\mathrm{D}\left({ }^{3} \mathrm{He}, \mathrm{p}\right){ }^{4} \mathrm{He}$. In NRA, a $1.7-\mathrm{MeV}^{3} \mathrm{He}^{+}$beam was injected at $45^{\circ}$ and protons emitted at $174.3^{\circ}$ were detected by a solid-state detector. A proton energy spectrum was converted to a deuterium depth profile from the surface to 1.3 $\mu \mathrm{m}$-depth. The beam flux was restricted below $1 \times 10^{16} \mathrm{~m}^{-2} \mathrm{~s}^{-1}$ to avoid temperature increases in the sample. A typical dose for each NRA was $4 \times 10^{19} \mathrm{~m}^{-2}$. Additional effects of the ${ }^{3} \mathrm{He}$ beam to the irradiation damage would be small because the averaged displacement in a region of $0-0.8-\mu \mathrm{m}$ was only 0.03 for $10 \mathrm{NRA}$ measurements. It was much smaller than the 0.63 dpa minimum damage level in the present work. In sample A5, an area ratio of the W irradiation spots to the NRA beam spot is estimated to be 0.7 , which is taken into account in the depth profiling. The area ratio is 1 in samples A3 and A4. 
A feature of this system is that the depth profiles are measured under continuous deuterium charging from the plasma to the sample, which means that the deuterium concentration at steady-state can be observed. To achieve steady state, NRA was measured at an elapsed time of $2 \mathrm{ks}$ after sample temperature changes [12].

\section{Results and discussion}

\subsection{Deuterium depth profiles in A3 and A4}

Fig. 1 shows deuterium depth profiles in sample A4 at low temperatures before and after heating the sample to $600 \mathrm{~K}$. At first, deuterium atoms are present only on the surface by absorption. Due to the finite resolution of the NRA system, deuterium seems to be present at a negative depth. The average concentration of deuterium in the damage region from 0 to 0.3 $\mu \mathrm{m}$ is $2.4 \times 10^{24} \mathrm{~m}^{-3}$, where the amount of absorbed deuterium is excluded. As shown in Fig. 2 , it is much lower than the concentration of dissolved deuterium, $C_{s}$, in non-irradiated tungsten under the same plasma condition [12]. One reason may be that the number of the solution sites, where deuterium can be dissolved, is considerably decreased by the irradiation. Runs $2-5$ in Fig. 2 show that when the sample temperature was increased, the deuterium concentration continued to increase. At $550 \mathrm{~K}$, the deuterium concentration decreased monotonically with increased sample temperature due to quasi-equilibrium of trapping and detrapping. This indicates that the number of the deuterium traps increases by heating to 500 K. A similar phenomenon has been observed in ${ }^{4} \mathrm{He}-$ and $\mathrm{H}$-irradiated tungsten [7]. This temperature corresponds to a recovery stage III of interstitial migration; thus, traps are considered to be associated with interstitial clusters which originate from the irradiation damage and grow during stage III [7].

Fig. 3 shows the depth profile of trapped deuterium in sample A4. This profile is obtained by subtracting the amount of absorbed deuterium on the surface and the uniform 
profile of dissolved deuterium in bulk from the observed depth profile. Positive values in the concentration over the NRA range indicate that the solution site has been fully recovered during $600 \mathrm{~K}$ heating. Distributions of $\mathrm{W}$ ions and atomic displacement estimated by the SRIM code [8] are also shown in Fig. 3. It is clear that trapped deuterium distributes over the damage region. This is because some interstitial atoms migrate toward a greater depth to produce traps during the stage III. As the peak depth of displacement is very shallow, interstitial atoms tend to disappear at the surface sink and hence the peak position of the trap shifts slightly deeper.

The depth profile of trapped deuterium in sample A3, shown in Fig. 3, is very similar to that in sample A4. However, the concentration peak in A4 is 1.4 times higher than A3 and the irradiation dose is 7 times higher. The amount of traps is not proportional to displacement, which will be discussed in Section 3.4.

\subsection{Deuterium depth profiles in $\mathrm{A5}$}

Compared to A3 and A4, A5 is heavily irradiated with $\mathrm{W}$ and its average damage level is 54 dpa. The depth profile of trapped deuterium shown in Fig. 4 varies from that shown in Fig. 3. The peak depth of trapped deuterium agrees with that of the displacement damage. The damage region is far enough from the surface so annihilation of the interstitials at the surface does not affect the trap distributions. A small peak appears around a depth of $0.6-\mu \mathrm{m}$. As the statistical error of each point at this depth is $10 \%$ and the data points form a smooth profile, this peak is significant. A possible reason for the peak is that the migration of the trap decelerates in the non-irradiated region and the traps accumulate at the boundary between the irradiated and non-irradiated regions. A large amount of self ions would also contribute to the peak. 
The temperature dependence of the average concentration of deuterium in bulk is shown in Fig. 5. The bulk is taken as the damaged region from 0 to $0.8 \mu \mathrm{m}$ in depth. In Run 1, no deuterium atoms are present in the bulk and the data point is outside of the figure. As in the case of $\mathrm{A} 4$, the deuterium concentration increases with temperature (Runs $2-7$ ). The temperature dependence of the deuterium concentration over $550 \mathrm{~K}$ is, however, different from that of A4. This suggests that properties of the traps vary with the damage level.

\subsection{Trapping energy}

As the sample is continuously charged with deuterium from the plasma, there is a quasiequilibrium both in solution and trapped. The equilibrium constant $f$ is expressed by [13]

$$
f=C_{s}\left(C_{0}-C_{t}\right) / h N C_{t}
$$

Here $C_{0}$ and $C_{t}$ are the trap density and the concentration of trapped deuterium, respectively. $h N$ is the density of the solution sites where $h$ is the number of solution sites per host atom and $N$ is the atomic density. A hydrogen atom is generally located at tetrahedral sites in bcc metals [14] so $h$ is taken as 6. $f$ is related to the trapping energy $E_{t}$ by

$$
f=\mu \exp \left(-E_{t} / k T\right)
$$

where $\mu$ is the pre-exponential factor representing an entropy difference, $k$ the Boltzmann constant and $T$ the temperature. In the right side of Eq. (1), $C_{s}$ is known from our previous work under the same experimental conditions [12] as is shown in Figs. 2 and 5. $C_{t}$ is the average concentration of trapped deuterium in the damaged region. $C_{0}$ is taken as $C_{t}$ at lower temperatures where all the traps become occupied by deuterium due to a potential barrier. Data of $f$ in A3 and A4, determined by substituting the above parameters into Eq. (1), are plotted in Fig. 6. By fitting the data to Eq. (2), it is found that $E_{t}$ and $\mu$ are $0.70 \mathrm{eV}$ 
and 4 for A3, 0.70 and 70 for A4, respectively (see Table 2). The values of $E_{t}$ agree with each other, indicating that the same type of the trap is dominant in A3 and A4, which is reasonable because the experimental conditions for A3 and A4 are the same except for the irradiating dose. The trapping energy, $E_{t}$, in the present work is an enthalpy difference of deuterium in the solution site and the trap. So the detrapping energy, $E_{e}$, often referred in the literature, is a sum of $E_{t}$ and the potential barrier from the solution site to the trap, $E_{p}$. When $E_{p}$ is assumed to be the same as activation energy of diffusion $E_{D}, 0.39 \mathrm{eV}[15], E_{e}$ is $1.1 \mathrm{eV}$. This value is somewhat smaller than values in other researchers' works (i.e., 1.4 $\mathrm{eV}$ by Oliver et al. [2], $1.43 \mathrm{eV}$ by Eleveld and van Veen [16], and $1.34 \mathrm{eV}$ by Poon et al. [17]). One reason may be that $E_{p}$ is higher than $E_{D}$ (e.g., by $\left.0.2-0.3 \mathrm{eV}\right) . E_{t}$ in the present work is not influenced by $E_{p}$, because it is determined in the quasi-equilibrium state while $E_{e}$, determined by kinetic methods such as desorption spectroscopy, includes $E_{p}$.

The entropy term of $\mu$ is quite different between A3 and A4. When the trapping site is a point-defect-like site, $\mu$ is considered to be close to unity [18]. This is the case of A3 where the damage level is low and thus the irradiation-induced defects remain small. The damage level in A4 is much higher than in A3 and the defects would grow larger. It is likely that the large value of $\mu$ is attributed to a large size of the defects. The size effect is also seen in other samples. As a collision cascade in $\mathrm{H}$-irradiated $\mathrm{B} 2$ is small due to low irradiation energy and light ion projectile, $\mu$ is a minimum value of 2 in all the samples. $\mu$ shows medium values in He-irradiated A1 and A2. A reason for difference between A1 and A 2 would be that A2 is irradiated at the stage III temperature and the defects effectively grow during the irradiation.

$f$ cannot be determined in sample A5 since the deuterium concentration above $550 \mathrm{~K}$ does not decrease significantly as shown in Fig. 5. According to Eq. (1), this temperature 
dependence indicates that $f$ is smaller than other samples since $C_{s} / h N$ is considered to be constant under the same experimental conditions. A reason is not clear but it is noted that a small value of $f$ (i.e., a large value of the trapping energy) indicates a deep trap (e.g., a void) [17].

\subsection{Trap density}

Trap density, $C_{0}$, is a very important parameter directly related to tritium retention. Fig. 7 plots $C_{0}$ data (plotted as a function of the damage level $Q$ )along with $C_{0}$ data from the literature. To aid in data comparison, an average number of dpa in the damage region is used for $Q$ because a peak number, often used by others, does not represent the total amount of displacement. In the literature, $Q$ is computed using a displacement energy of $90 \mathrm{eV}$. The vertical axis of $C_{0}$ is an averaged value in the damaged region. In Wampler's work [4], the damage region is $2.5 \mu \mathrm{m}$ and a difference in the average deuterium concentration between irradiated and non-irradiated Plansee $\mathrm{W}$ samples at $473 \mathrm{~K}$ is regarded as $C_{0}$. In Tyburska's work [5], the damage region is $0.8 \mu \mathrm{m}$ and a difference in the average deuterium concentration between non-annealed and annealed samples exposed to $38 \mathrm{eV}-\mathrm{D}$ at $320-350$ $\mathrm{K}$ is regarded as $C_{0}$. Note that the concentration in the damage region is not known from the literature and a probe depth of $7 \mu \mathrm{m}$ is used as the average region for $C_{0}$. Thus $C_{0}$ in Tyburska's work is underestimated here. In Fukumoto's work [3], the damage region is 1.5 $\mu \mathrm{m}$ for $300-\mathrm{keV}$ irradiation and the average deuterium concentration in the deuteriumimplanted sample with a dose of $8 \times 10^{24} \mathrm{~m}^{-2}$ is regarded as $C_{0}$. The values of $C_{0}$ and $Q$ of A1, A2, and B2 are slightly different from those listed in Table 2 of our previous work [7] because of a difference in the average region of $0.3-1.2 \mu \mathrm{m}$ from that in the present work. 
It is clear that dependence of $C_{0}$ on $Q$ changes at $0.1 \mathrm{dpa}$. Considering that the peak damage is several times higher than $Q$, a collision cascade is suggested to overlap with a damaged region and new displacement atoms would not be effectively produced at this damage level. $C_{0}$ gradually increases with $Q$ over 0.1 dpa and does not tend to be saturated up to 54 dpa. As Tyburska's data should be actually higher, all the data seems to lie on one line except for sample A2 and Fukumoto's data. A2 is irradiated at a high temperature of 573 $\mathrm{K}$ and the temperature in the Fukumoto's sample is increased due to the high flux irradiation. This is due to high trap density, because the trap is effectively produced by irradiation at temperatures of the recovery stage III [7]. In this stage, interstitial atoms annihilate at sinks, such as vacancies, or cluster to form small interstitial clusters and dislocation loops. The former increases the chances for new displacement and the latter increases the trap density.

In general, the trap in irradiated tungsten is considered to be a vacancy or vacancy clusters $[2,6,16,17]$. However, that is not the case in the present work. One plausible explanation is that the trap is a point-defect-like site (e.g., a vacancy, vacancy clusters, and lattice distortion) accompanying the interstitial dislocation loops.

\section{Summary}

Characteristics of hydrogen traps in ion-irradiated tungsten (e.g., the trapping energy, depth profiles of trapped deuterium, and evolution of the trap density with displacement) were experimentally investigated. The irradiation energy and the average damage level are 1.5 MeV and 0.63 dpa for sample A3, 1.5 MeV and 4.2 dpa for A4, and 5.0 MeV and $54 \mathrm{dpa}$ for A5, respectively. The results show that traps are produced during sample heating around $500 \mathrm{~K}$ after the irradiation at room temperature. This is related to recovery stage III of interstitial migration. It is likely to that the trap is a point-defect-like site accompanying interstitial clusters (e.g., the dislocation loops). The trapping energy, an enthalpy difference 
between the solution site and the trap, is $0.70 \mathrm{eV}$ and independent of the irradiating conditions, which suggest that there is only one type of trap. The entropy term of the equilibrium constant varies with the irradiating ions and doses, which would be attributed to the size of the defects.

The trap density increases with the damage level and reaches $8.3 \times 10^{26} \mathrm{~m}^{-3}(1.3$ at. \%) at an average of $54 \mathrm{dpa}$. It is found that the gradient of the increase becomes gradual over 0.1 dpa, probably due to overlapping of the collision cascades. This result indicates that, in fusion devices, traps are effectively produced under high temperature irradiation but tritium retention does not significantly increase, even under heavy irradiation. The temperature history of a tungsten wall will be important for evaluation of the tritium retention and the damage level.

\section{Acknowledgement}

This work is supported by a Grant-in-aid for Scientific Research for Priority Area 476, "Tritium Science and Technology for Fusion Reactor." 


\section{References}

[1] V.Kh. Alimov, J. Roth, Phys. Scr. T128 (2007) 6.

[2] B.M. Oliver, R.A. Causey, S.A. Maloy, J. Nucl. Mater. 329-333 (2004) 977.

[3] M. Fukumoto, H. Kashiwagi, Y. Ohtsuka, et al., J. Nucl. Mater. 390-391 (2009) 572.

[4] W.R. Wampler, R.P. Doerner, Nucl. Fusion 49 (2009) 115023.

[5] B. Tyburska, V.Kh. Alimov, O.V. Ogorodnikova, et al., J. Nucl. Mater. 395 (2009) 150.

[6] G.M. Wright, M. Mayer, K. Ertl, et al., Nucl. Fusion, 50 (2010) 075006.

[7] I. Takagi, K. Yamamichi, R. Imade, et al., Fusion Sci. Technol. 60 (2011) 1451.

[8] http://srim.org.

[9] O.V. Ogorodnikova, B. Tyburska, V.Kh. Alimov, et al., J. Nucl. Mater. 415 (2011) S661.

[10] I. Takagi, K. Yoshida, K. Shin, et al., Nucl. Instr. Methods Phys. Res. B84 (1994) 393.

[11] M. Akiyoshi, H. Sakamoto, R. Haraguchi, et al., Nucl. Instr. Methods Phys. Res. B232 (2005) 173.

[12] I. Takagi, R. Imade, Y. Ikegami, et al., J. Nucl. Mater. 417 (2011) 564.

[13] I. Takagi, J. Nucl. Sci. Technol. 29 (1992) 947.

[14] H.-D. Carstanjen, Phys. Stat. Sol. (a) 59 (1980) 11.

[15] R. Frauenfelder, J. Vac. Sci. Technol. 6 (1969) 388.

[16] H. Eleveld, A. van Veen, J. Nucl. Mater. 191-194 (1992) 433.

[17] M. Poon, A.A. Haasz, J.W. Davis, J. Nucl. Mater. 374 (2008) 390.

[18] I. Takagi, M. Akiyoshi, N. Matsubara, et al., J. Nucl. Mater. 367-370 (2007) 489. 


\section{List of Figures}

Fig.1. Deuterium depth profiles in sample A4 at Run 1 (at $373 \mathrm{~K}$ after 1.5-MeV W irradiation at room temperature) and Run 12 (at $378 \mathrm{~K}$ after heated up to $600 \mathrm{~K}$ ). The run number represents a temperature sequence denoted in Fig. 2.

Fig. 2. Temperature dependence of the deuterium concentration in the damaged region in sample A4 irradiated with 1.5-MeV W. Numbers denotes a temperature sequence.

Fig.3. Depth profiles of trapped deuterium at $378 \mathrm{~K}$ in $1.5-\mathrm{MeV} \mathrm{W}$ irradiated samples of A3 and A4. Distributions of atomic displacement and W ion estimated by the SRIM code are also shown in arbitrary unit.

Fig. 4. A depth profile of trapped deuterium at $376 \mathrm{~K}$ in 5.0-MeV W irradiated sample of A5. Distributions of atomic displacement and W ion estimated by the SRIM code are also shown in arbitrary unit.

Fig. 5. Temperature dependence of the deuterium concentration in the damaged region in sample A5 irradiated with 5.0-MeV W.

Fig. 6. Equilibrium constant of deuterium between the solution site and trap in ion-irradiated tungsten.

Fig. 7. Evolution of the trap density with atomic displacement in $\mathrm{W}-,{ }^{4} \mathrm{He}-$ and $\mathrm{H}$-irradiated tungsten together with the data of other literatures. 
Table 1 List of W samples in this study and previous studies.

\begin{tabular}{|c|c|c|c|c|c|c|}
\hline \multirow{2}{*}{$\begin{array}{l}\text { Sample } \\
\text { No. }\end{array}$} & \multicolumn{4}{|c|}{ Irradiation conditions } & \multicolumn{2}{|c|}{ Displacement $^{\mathrm{a}}$ (dpa) } \\
\hline & Ion & $\begin{array}{l}\text { Energy } \\
(\mathrm{MeV})\end{array}$ & $\begin{array}{l}\text { Dose } \\
\left(\mathrm{m}^{-2}\right)\end{array}$ & $\begin{array}{c}\text { Temp. } \\
(\mathrm{K})\end{array}$ & Peak & Average (Range) \\
\hline A1 & $\mathrm{He}-4$ & 0.8 & $1.2 \times 10^{21}$ & 393 & 0.99 & $0.51(1.3 \mu \mathrm{m})$ \\
\hline $\mathrm{A} 2$ & $\mathrm{He}-4$ & 0.8 & $1.2 \times 10^{21}$ & 573 & 0.99 & $0.51(1.3 \mu \mathrm{m})$ \\
\hline A3 & $\mathrm{W}$ & 1.5 & $3.0 \times 10^{18}$ & RT & 1.6 & $0.63(0.3 \mu \mathrm{m})$ \\
\hline A4 & $\mathrm{W}$ & 1.5 & $2.0 \times 10^{19}$ & RT & 11 & $4.2 \quad(0.3 \mu \mathrm{m})$ \\
\hline A5 & $\mathrm{W}$ & 5.0 & $2.6 \times 10^{20}$ & RT & 110 & $54.4 \quad(0.8 \mu \mathrm{m})$ \\
\hline B2 & $\mathrm{H}$ & 0.2 & $1.0 \times 10^{23}$ & 400 & 5.9 & $2.7 \quad(1.0 \mu \mathrm{m})$ \\
\hline
\end{tabular}

a Data of A1, A2, B2 are taken from our previous work [7].

b Displacement energy is $90 \mathrm{eV}$.

Table 2 Trap parameters

\begin{tabular}{|cccccccc|}
\hline $\begin{array}{l}\text { Sample } \\
\text { No. }{ }^{-}\end{array}$ & \multicolumn{3}{c}{ Irradiation conditions } & \multicolumn{3}{c|}{ Trap parameters } \\
\cline { 2 - 8 } & Ion & $\begin{array}{c}\text { Energy } \\
(\mathrm{MeV})\end{array}$ & $\begin{array}{c}\text { Average } \\
\text { disp. }(\mathrm{dpa})\end{array}$ & $\begin{array}{c}\text { Temp. } \\
(\mathrm{K})\end{array}$ & $\begin{array}{c}C_{\mathrm{o}} \\
\left(\times 10^{26} \mathrm{~m}^{-3}\right)\end{array}$ & $\begin{array}{c}E_{\mathrm{t}} \\
(\mathrm{eV})\end{array}$ & $\mu$ \\
\hline A1 & He-4 & 0.8 & 0.51 & 393 & 4.4 & 0.70 & 5 \\
$\mathrm{~A} 2$ & $\mathrm{He}-4$ & 0.8 & 0.51 & 573 & 7.3 & 0.70 & 10 \\
$\mathrm{~A} 3$ & $\mathrm{~W}$ & 1.5 & 0.63 & $\mathrm{RT}$ & 4.0 & 0.70 & 4 \\
A4 & W & 1.5 & 4.2 & $\mathrm{RT}$ & 5.1 & 0.70 & 50 \\
A5 & W & 5.0 & 54.4 & RT & 8.3 & - & - \\
B2 & H & 0.2 & 2.7 & 400 & 4.1 & 0.70 & 2 \\
\hline
\end{tabular}

a Data of A1, A2, B2 are taken from our previous work [7]. 


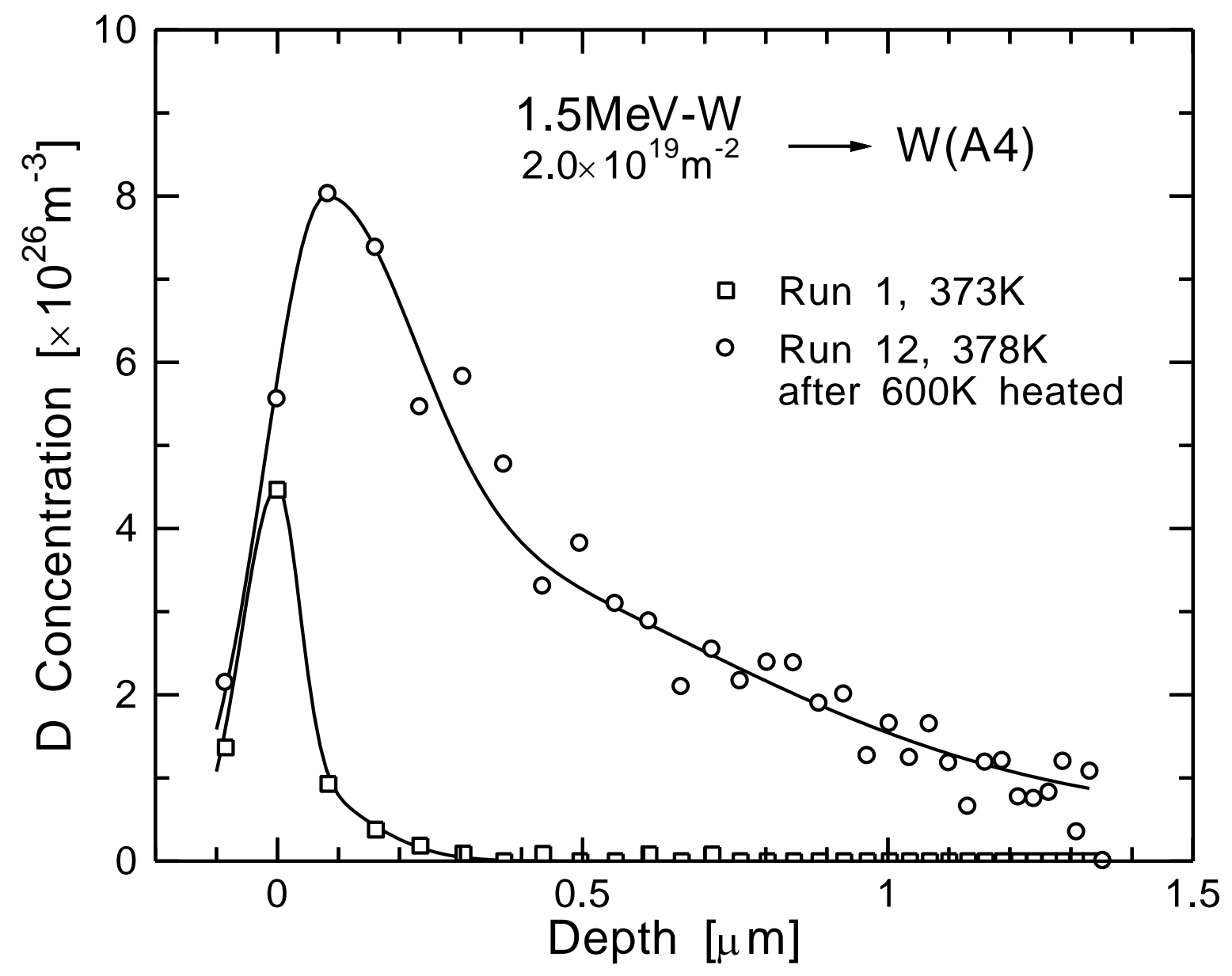

Fig.1 


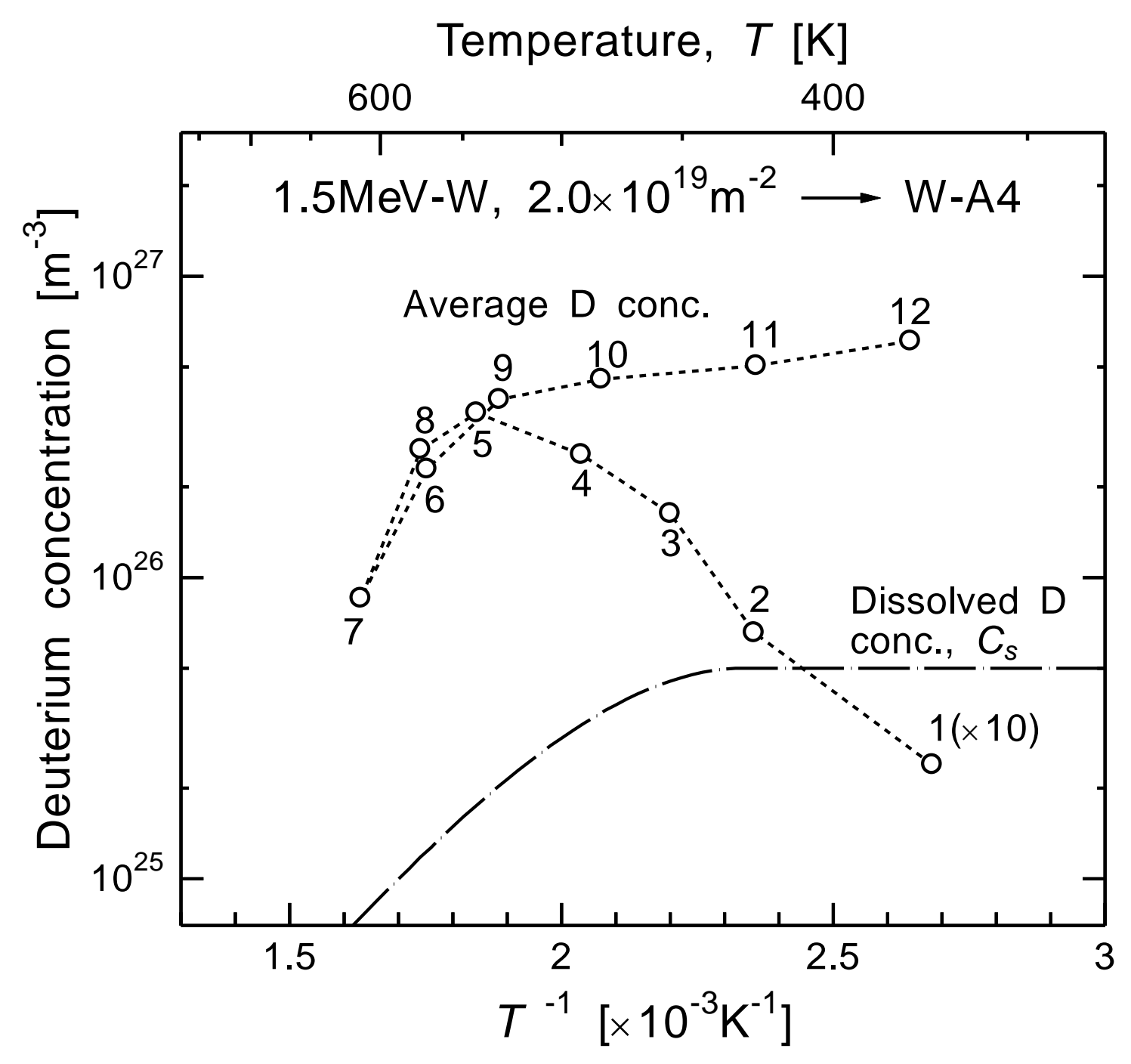

Fig.2 


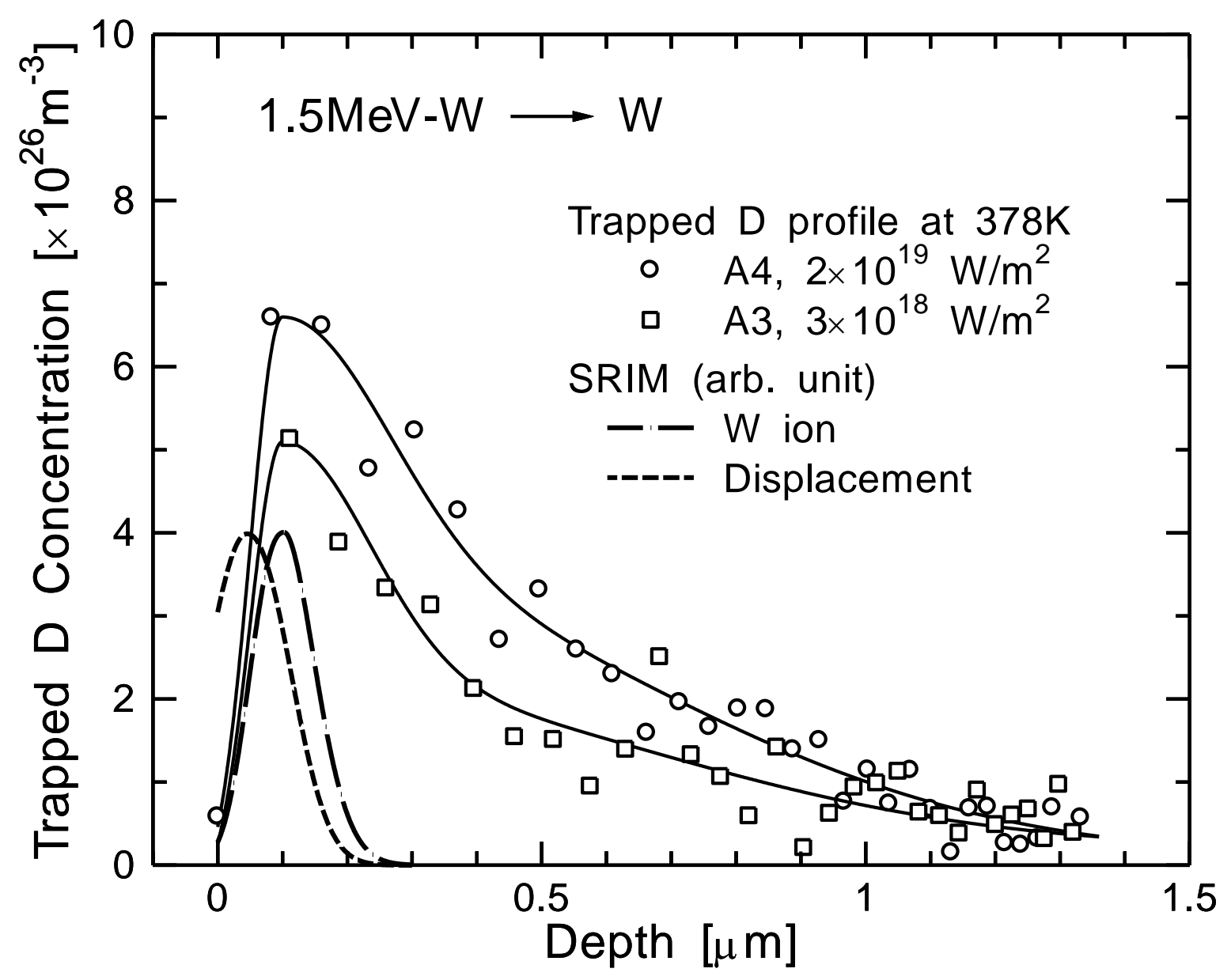

Fig.3 


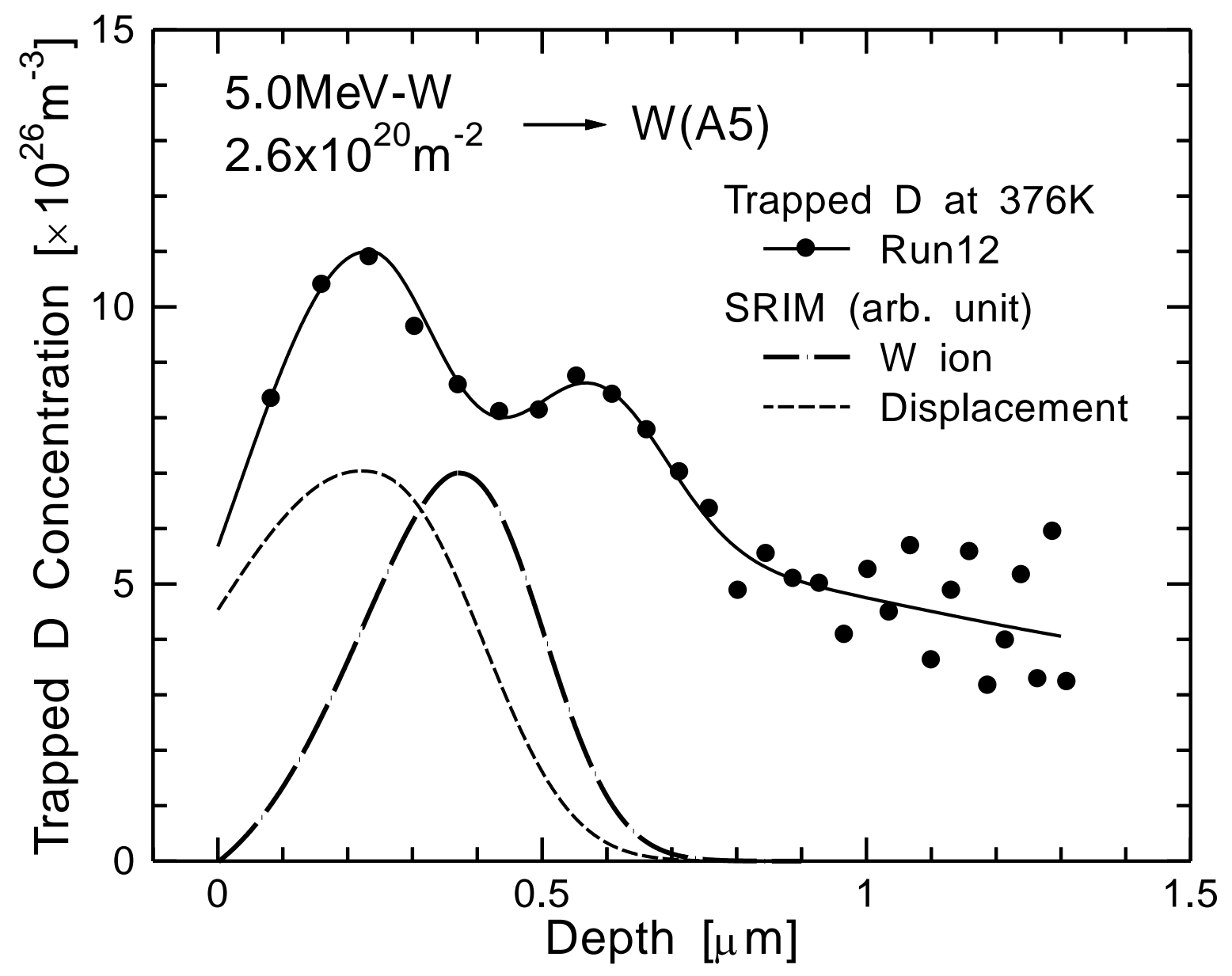

Fig.4 


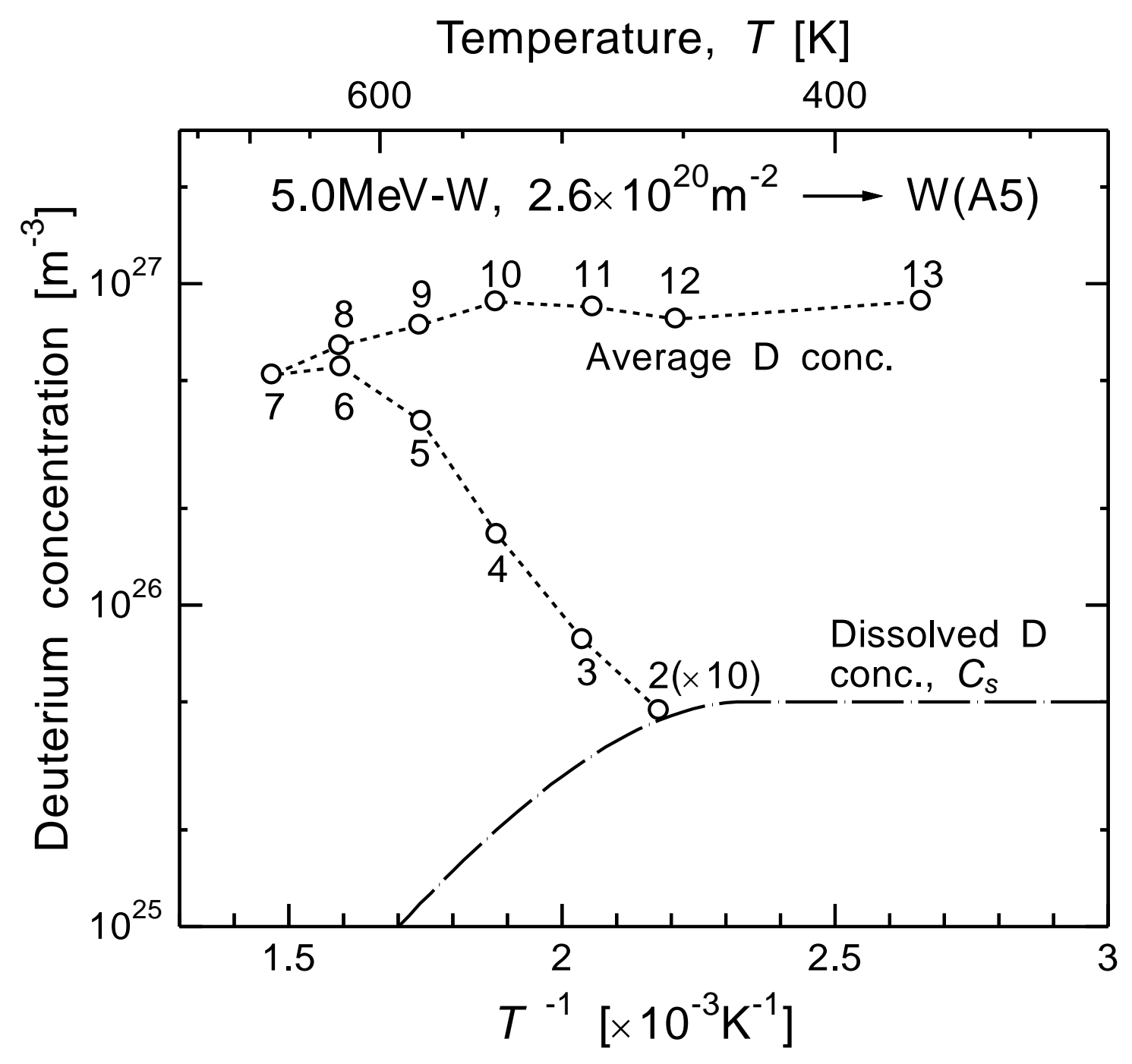

Fig.5 


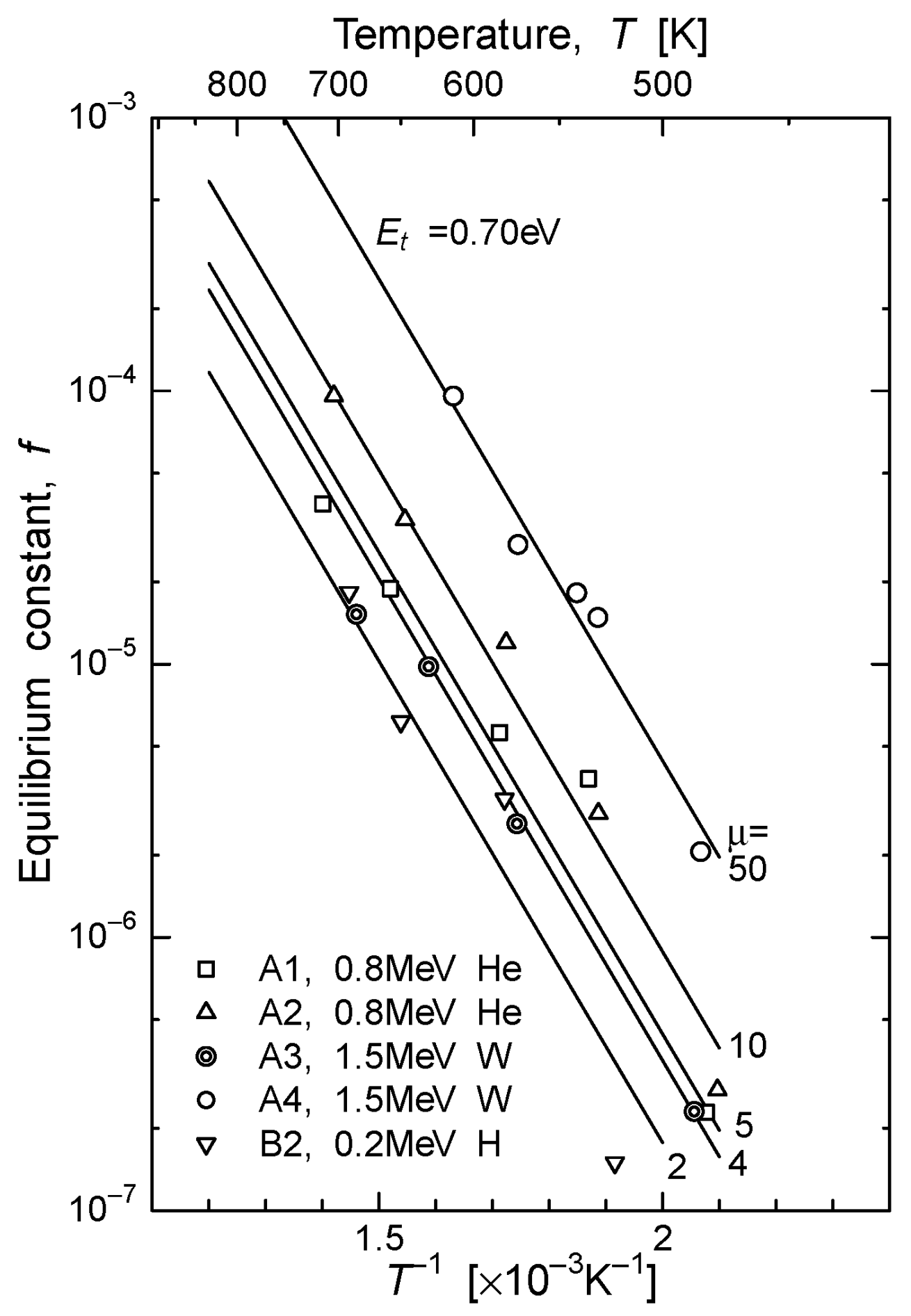

Fig.6 


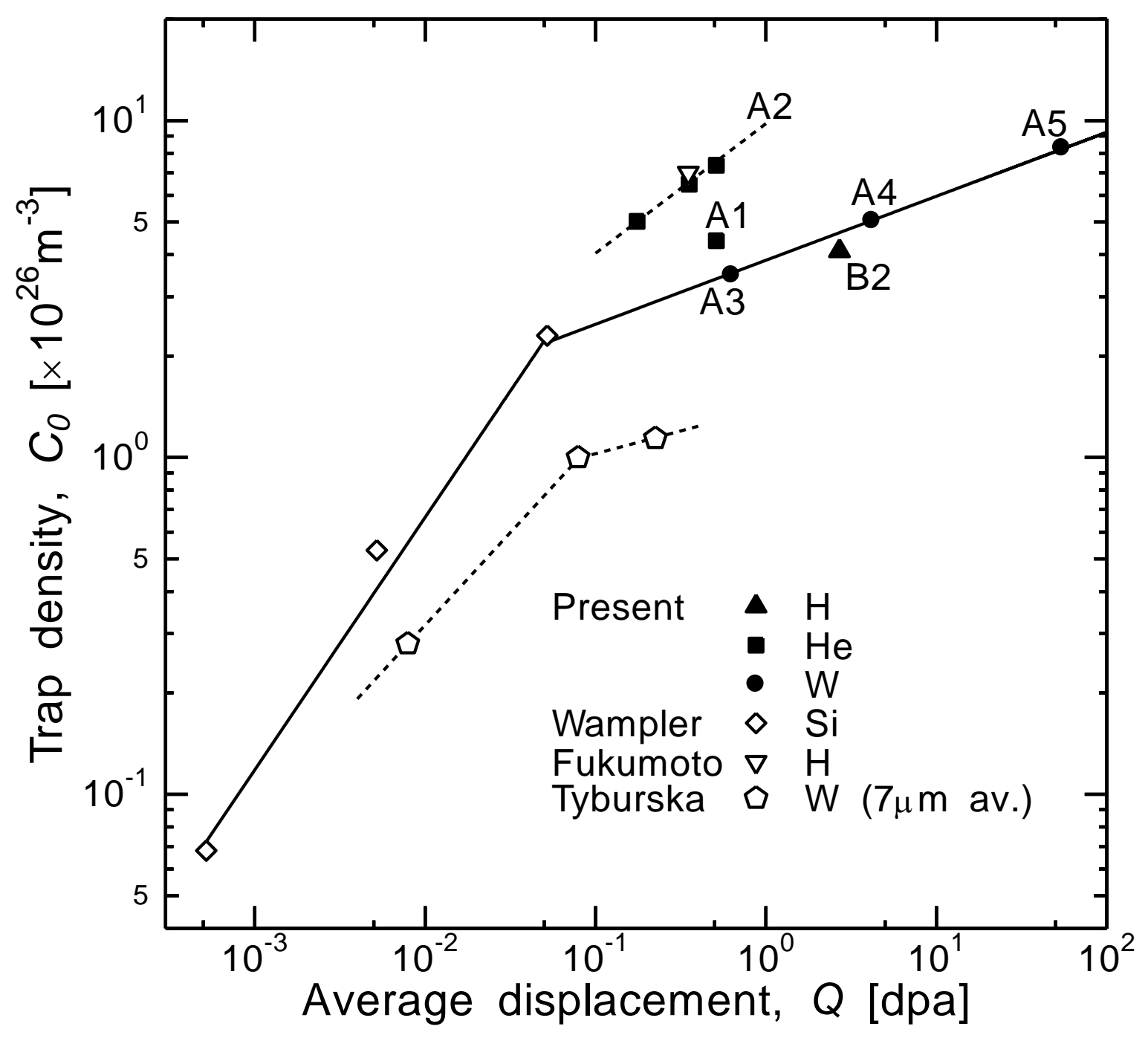

Fig.7 